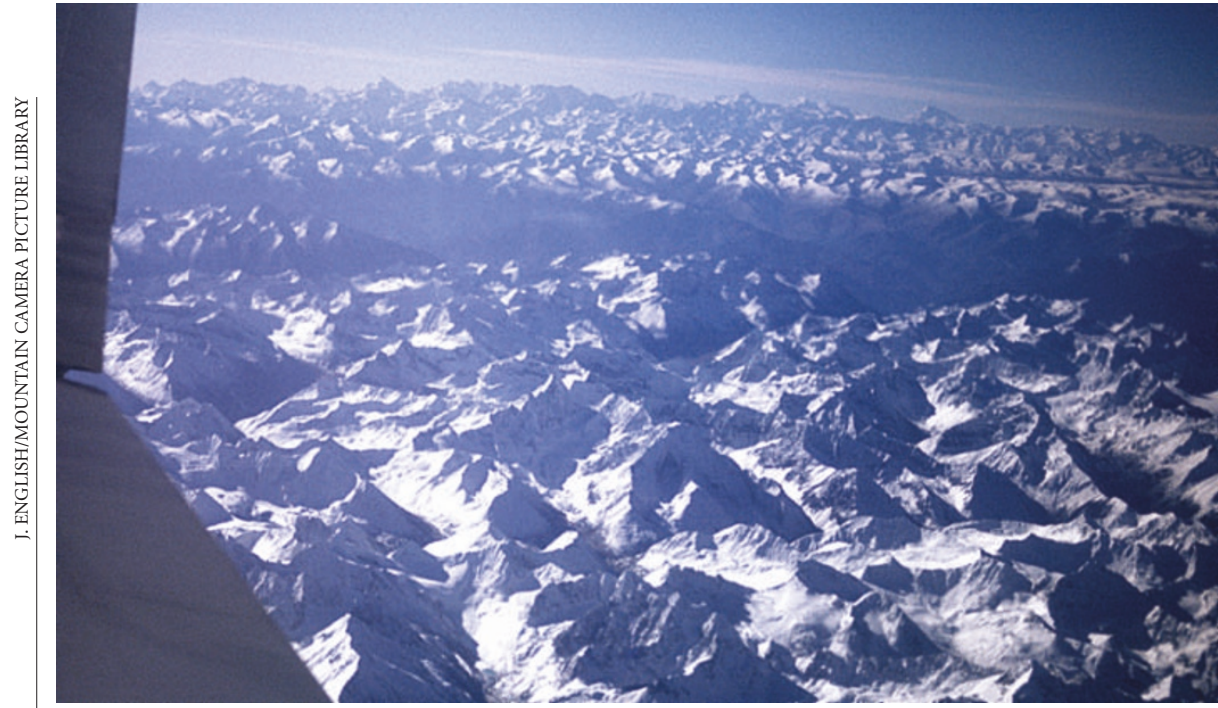

Peak practice: geologists will carry out a ground-breaking project in a remote part of the Himalayas.

\section{India and China mount joint quake study in the Himalayas}

\section{K.S. Jayaraman, New Delhi}

The region of the Himalayas where Indian and Chinese troops fought 42 years ago is set to be the site of another meeting between the two nations - this time of their geologists.

The geologists will carry out a two-year study of a part of the mountain range called the Eastern Himalayan Syntaxis. This region, comprising southwest China, northeast India and northern Myanmar (see map, right), is so physically and politically inaccessible that it remains poorly studied by ground-based research.

This is about to change, thanks to an agreement between India's Department of Science and Technology and the Chinese Academy of Sciences, forged by meetings in April and August of this year.

"This region is vital to both India and China as most of the severe earthquakes in this part of the world come from here," says Baldev Arora, director of the Wadia Institute of Himalayan Geology in Dehra Dun, India. He will coordinate the study with Bai Denghai of the Institute of Geology and Geophysics in Beijing, China.

The area is prone to earthquakes because of interactions between the tectonic plates holding India and China, which collided to force up the bulk of the Himalayas, and a block of land including southeastern China and Myanmar. The main collision has been well studied, says Bai, but little is known about the interaction of the plates with the land to the east.

Some studies suggest that the Himalayas are overriding southeastern China. "This is one thing we want to confirm," says Bai. The geologists will also try to verify whether a 'plume' of heat from deep within the mantle wells up beneath the region, as some Chinese scientists have suggested.

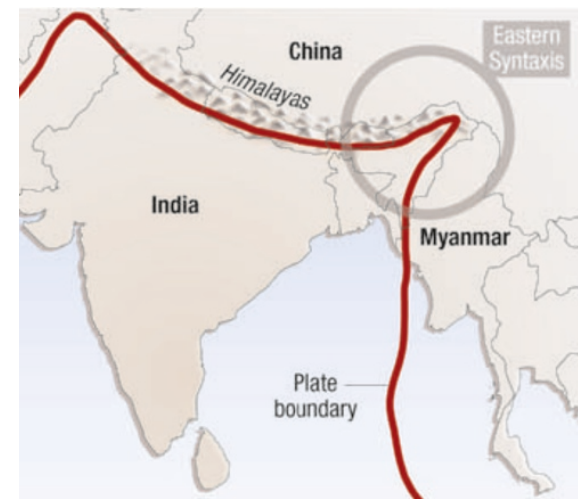

Most of the existing information about the Eastern Himalayan Syntaxis comes from satellites, or from seismometers placed hundreds of kilometres away. The joint study will supplement this with geophysical and geological field data to help construct a threedimensional model of the region.

Instruments will be placed in a corridor running from Arunachal Pradesh in India, through Myanmar to southwestern China. Scientists will collect data in their own section of this corridor, except in Myanmar, where agreements will allow Indian and Chinese scientists to work side by side. "Once the field measurements are done, the data will be processed jointly to obtain a unified model of the collision zone," says Arora.

This arrangement may sound less than ideal for a joint project but, given the political circumstances, it is a "practical approach", says Arora. He thinks the level of cooperation will increase once the proposed Joint Steering Committee, co-chaired by science ministers of the two countries, is put in place early in 2005 (see Nature 432, 427; 2004).

Details of the study are set to be finalized at a meeting in February, with the work expected to be completed in 2007.

\section{Grads rally round student in Toronto harassment case}

Erika Check, Washington

Canadian graduate students have voiced support for a complaint against the University of Toronto, Ontario, about its handling of a sexual harassment case.

On 27 November, Canada's National Graduate Caucus passed a motion of support for claims filed in May by Gwen Schwartz with the Ontario Human Rights Commission (OHRC). Schwartz alleges that her former graduate adviser sexually harassed her and that she suffered reprisals when she raised the issue with administrators. She also alleges that she has been blocked from retrieving her data from her former adviser (see Nature 430, 711 and $958 ; 2004)$. The OHRC is considering a formal investigation of her complaints about the university and its affiliated hospital group, the University Health Network (UHN).

The caucus, a component of the Canadian Federation of Students, represents about 60,000 graduate students. Its motion supports Schwartz's OHRC complaints and calls on the university to help her regain her data.

"It's important that Gwen knows that she has support," says Rose Da Costa, resource coordinator for the University of Toronto Graduate Students' Union. "She has gone through a very serious situation and has not achieved a satisfactory resolution.” Da Costa raised the motion of support at the national caucus after successfully passing a similar motion at Toronto.

Both the hospital and the university believe that a settlement they negotiated with Schwartz and several other parties last year, after a mediation process, resolved the issues. Schwartz disputes the settlement, claiming that she does not agree with its terms and felt pressured to sign it. However, both the UHN and the University of Toronto consider it final and binding. Because of the possible OHRC investigation, UHN lawyers said the hospital would not comment for this report.

The University of Toronto also said it would not comment on the caucus's motion. However, it "vigorously denies" Schwartz's allegations and says it has always acted appropriately. "The university has met all its obligations under the agreement, including financial and academic support for Ms Schwartz to enable her to move forward with her studies," says Angela Hildyard, vice-president of human resources. 